\title{
Influence of different stabilizers on the morphology of gold nanoparticles
}

\author{
Amal M. Ibrahim ${ }^{1,2^{*}} \mathbb{D}$, Hind A. A. Alzahrani ${ }^{3}$, Mona Mahmoud Abd El-Latif ${ }^{4}$ and Mohamed Mohamed Selim²
}

\begin{abstract}
Objectives: The current study revealed that the used stabilizers greatly affect the morphology as well as the aspect ratio of the obtained gold nanoparticles.

Background: Control of the morphology and dimensions of gold nanoparticles during the preparation is an important task for targeting certain applications in demand.

Material and methods: Gold nanoparticles were prepared by the reduction of tetrachloroauric(III) acid in the presence of different stabilizers: polyethyleneimine (PEI), polyvinylpyrrolidone (PVP), and chitosan.

Results: In the case of using polyethyleneimine, the produced nanoparticles showed a homogenous spherical structure. Meanwhile, in the case of using polyvinylpyrrolidone and chitosan, the produced nanoparticles experience non-homogenous morphology with great diversity. Transmission electron microscopy (TEM) and UVvisible spectrophotometry (UV-vis) techniques were employed to study the criteria of the obtained gold nanoparticles.
\end{abstract}

Conclusions: It was obviously concluded that the type and concentration of the reducing agents that were added during gold preparation and acted as stabilizer templates affect to a great extent the morphology and particle shape. Also, stabilizers affect the homogeneity of the produced gold nanoparticles. In the case of using polyethyleneimine, the produced nanoparticles showed a homogenous spherical structure. Meanwhile, in the case of polyvinylpyrrolidone and chitosan, the produced nanoparticles experience non-homogenous morphology with great diversity.

Keywords: Gold nanoparticles, Stabilizer, Aspect ratio, Transmission electron microscopy

\section{Background}

Nanogold is one of the most important noble metal nanoparticles that attracts the attention of scientists around the world. Even though the majority of researches concerned its applications in the medical field, nanogold has a wide variety of applications such as catalysis (Huang et al. 2012; Mallat and Baiker 2004; Obradović and Gojković 2013; Panjan et al. 2012), drug delivery systems (Huang et al. 2006; Norman et al. 2008; Stone et al. 2011), sensors (Pérez et al. 2015; Wu and Tseng 2011), and cancer diagnosis and therapy (Pérez et al. 2015; Arachchige et al. 2015; Suneetha et al. 2014).

\footnotetext{
*Correspondence: amozarei@gmail.com; Aabougamil@uj.edu.sa

${ }^{1}$ Chemistry Department, Faculty of Science, University of Jeddah, Jeddah,

Saudi Arabia

${ }^{2}$ Laboratory of Surface Chemistry and Catalysis, Department of Physical

Chemistry, National Research Center, Al Buhouth St., Cairo, Egypt

Full list of author information is available at the end of the article
}

This wide range of applications of nanogold is devoted to its unique Optical as well as Thermal properties, controllable aspect ratio, and low toxicity (Allen et al. 2017). There are many studied techniques for the preparation of nanogold. These include a green biochemical method (Abdel-Raouf et al. 2017; Chen et al. 2001; Pol et al. 2003; Reed et al. 2003), the seed-mediated mechanism (Brown and Natan 1998; Jana et al. 2001), photochemical reaction (Sau et al. 2001), phase transfer reaction (Esumi et al. 2000; Zhu et al. 2005), and many other techniques. Among these techniques, the stabilized reduction reaction using different types of polymeric materials is considered one of the promising preparation methods (Carotenuto and Nicolais 2004; Corbierre et al. 2001; Esumi et al. 2001a, b; Shimmin et al. 2004; Teranishi et al. 1998). There is a strong relationship between the morphology and dimensions of nanogold particles and 
their potential applications (Allen et al. 2017). For example, rod-like structure attracts scientists working in the field of chemistry and biotechnology as it is widely used in the diagnosis and treatment of cancer (Huang et al. 2012; Allen et al. 2017; Nikoobakht and El-Sayed 2003). In addition, spherical morphology was found to have antibacterial, antiviral, and catalytic activities. Meanwhile, former studies reported the utilization of the triangular and prism-like structures in catalysis and sensing applications (Alabbad et al. 2014; Mena et al. 2005; Zeng et al. 2011; Zheng et al. 2006). Nowadays, controlling the morphology and dimensions of nanogold particles during their preparation is an important goal to be achieved for the sake of their utilization in particular applications. The present work is concerned with studying the effect of different stabilizing polymers in the morphology and aspect ratio of the prepared gold nanoparticles. Gallic acid at room temperature has been used in the presence of polyethyleneimine (PEI), polyvinylpyrrolidone (PVP), and chitosan as organic stabilizers. The criteria of the produced gold nanoparticles were investigated using UV-vis spectrophotometry and transmission electron microscopy.

\section{Experimental}

\section{Materials}

About $0.3 \mathrm{mM}$ stock solution of tetrachloroauric(III) acid was provided from Sigma-Aldrich (molecular weight $=393.83 \mathrm{~g} / \mathrm{mole}$ ) used throughout the work; the solution was prepared by dissolving $0.1181 \mathrm{~g}$ $\mathrm{HAuCl}_{4} \cdot 3 \mathrm{H}_{2} \mathrm{O}$ in $1 \mathrm{~L}$ deionized water. This stock solution of gold(III) ions can be prepared in advance if stored in a brown bottle. The $0.25-\mathrm{mM}$ stock solution of gallic acid (molecular weight $=170.12 \mathrm{~g} / \mathrm{mole}$ ) was prepared by dissolving $0.0213 \mathrm{~g}$ of gallic acid in $500 \mathrm{~mL}$ deionized water. Polyethyleneimine, Polyvinylpyrrolidone, and Chitosan (Fig. 1) were provided from Acros Organic and usedas polymeric stabilizers.

\section{Characterization}

The UV-vis spectroscopy of the prepared samples was studied using UV-vis spectrophotometer (Perkin Elmer model GBC 902). The morphology of the prepared samples was studied by Jeol JEM transmission electron microscope (TEM) with Max. Mag. $600 \mathrm{kX}$ and resolution $0.2 \mathrm{~nm}$. For TEM measurements, the stabilized liquid samples were prepared by sonication for $30 \mathrm{~min}$.

\section{Methods}

Gold nanoparticles were synthesized (as reported elsewhere) (Ibrahim et al. 2016). The reaction was carried out in the presence of $1 \mathrm{ml}$ and $1 \mathrm{M}$ solution of PEI, PVP, and chitosan. It was observed that the solutions were changed from pink to wine red color with the addition of the stabilizers. The reactions were kept for $30 \mathrm{~min}$ at room temperature.<smiles>CCCNCCN(CCN)CCN(CCNCCN)CCNCCNCCN</smiles><smiles>CC(CCC(N1CCCC1=O)C(C)(C)C)N1CCCC1=O</smiles>

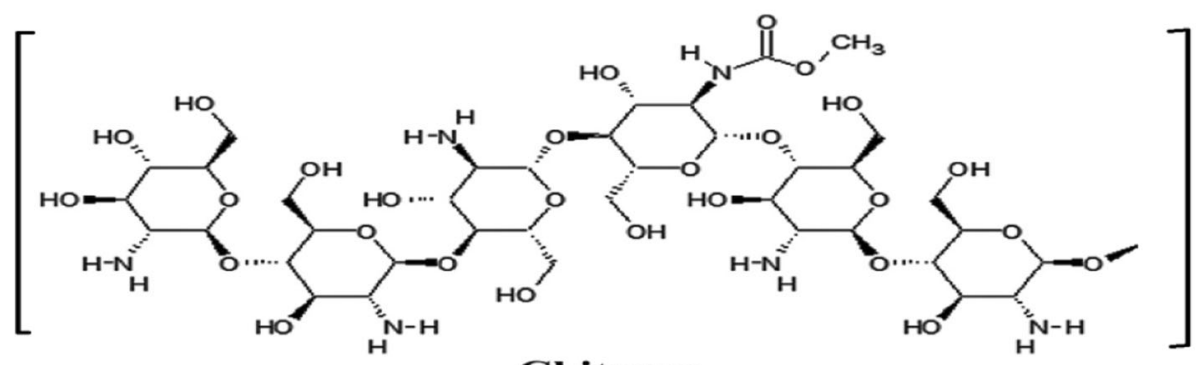

Fig. 1 Chemical structure of polyethyleneimine, polyvinylpyrrolidone, and chitosan 


\section{Results}

\section{Transmission electron microscopy}

Transmission electron microscopy images (Fig. 2) of the obtained gold nanoparticles using PEI, PVP, and chitosan showed that the used stabilizer influenced to a great extent the morphology and also the size of the obtained nanoparticles. Meanwhile, using PEI as stabilizer leads to the production of uniform spherical gold nanoparticles with an average diameter of $7 \mathrm{~nm}$; on the other hand, the use of PVP results in the appearance of different morphologies. Tetrahedral, double tetrahedral pyramid, and truncated tetrahedron morphologies appeared, but among them, the predominant morphology that appeared was the truncated tetrahedron. It was noticed that the particle size increased to $18 \mathrm{~nm}$ average size. Chitosan as stabilizers also showed the appearance of the tetrahedral, double tetrahedral pyramid, and truncated tetrahedron with the appearance of the rod-like structure. Also, it was noticed the increase of the particle size to $25 \mathrm{~nm}$ average particle size.

\section{Ultraviolet-visible spectroscopy}

The fact that the electron cloud in case of nanoparticles oscillates around the surface of the nanoparticle creates a phenomenon due to the absorbance of electromagnetic radiation-Surface Plasmon Resonance a phenomenen arised from the absorbance of electromagnetic radiation by the electron cloud oscillates around the surface of the nanoparticle. Figure 3 shows the UV-vis results of the obtained gold nanoparticles with PEI, PVP, and chitosan stabilizers; it was obviously in agreement with TEM results.

\section{Discussion}

The effect of PEI, PVP, and chitosan on the particle size and morphology of the produced gold nanoparticles

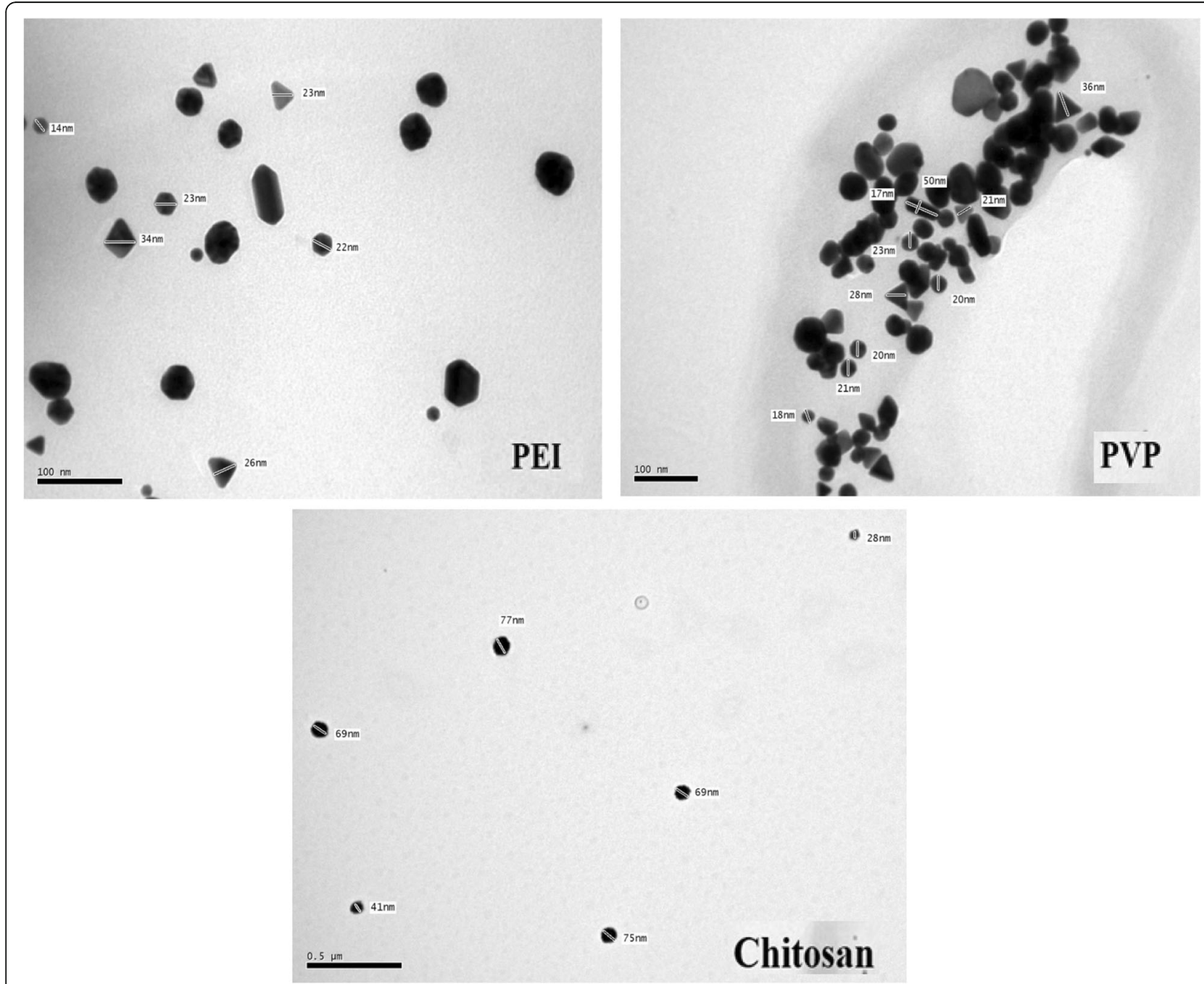

Fig. 2 TEM images of gold nanoparticles using PEI, PVP, and chitosan stabilizers 


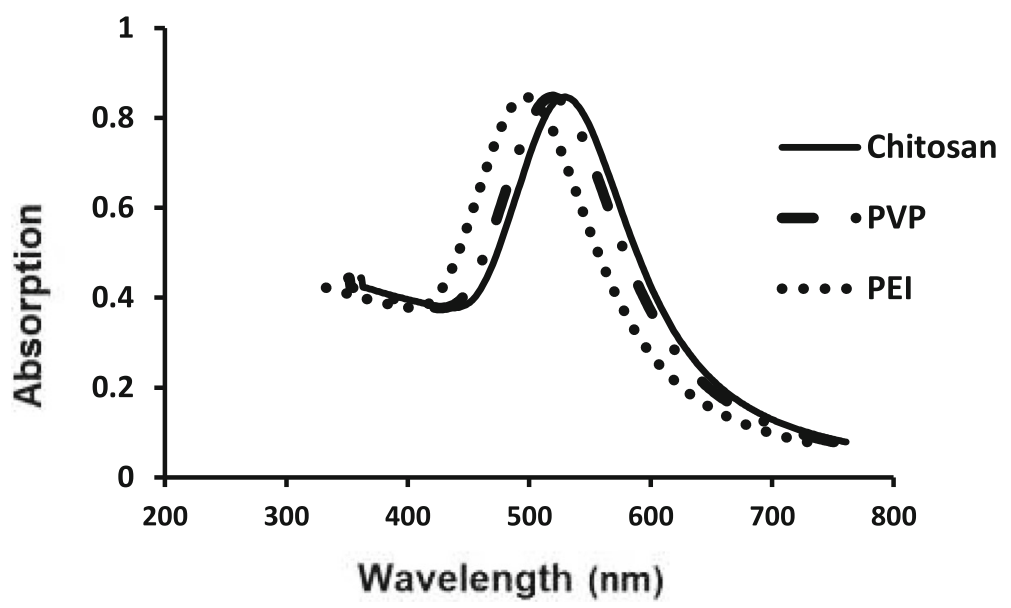

Fig. 3 UV-vis spectra of colloid solutions of gold nanoparticles stabilized by PEI, PVP, and chitosan

could be explained in terms of their chemical structure. The linearity of the chemical structure of PEI, without possessed ring moieties, enhances the uniformity of the produced gold nanoparticles and narrows the particle size range. Meanwhile, the presence of five-membered ring moiety and long chain structure in the case of PVP probably generates various lattice planes for gold nanoparticles to grow through, leading to the various morphologies that appeared, and the majority of the morphologies were closer to a spherical shape (Teranishi et al. 2000). In the case of chitosan stabilizer, it was noticed that the rode-like structure started to appear with a noticeable extent. The appearance of rode-like morphology may be explained by the fact that there is an electrostatic attraction force between the amino group in the structure of chitosan and the metal ion; this could enhance the crystal growth in the rod shape. In UV-visible study, the maximum absorbance of the sample using PEI is at $505 \mathrm{~nm}$. Meanwhile, with using PVP and chitosan, there is a red shift for the maximum absorbance to $510 \mathrm{~nm}$ and $537 \mathrm{~nm}$, respectively. This red shift is owing to the increase in the particle size and also the different aspect ratio (Philip 2008).

\section{Conclusions}

Gold nanoparticles were prepared from the reduction of tetrachloroauric(III) acid with gallic acid at room temperature in the presence of PEI, PVP, and chitosan as polymeric stabilizers. The used polymer affects extensively the shape and size of the produced gold nanoparticles. In the case of using PEI, the obtained gold nanoparticles showed almost complete homogeneity with a narrow particle size range. Meanwhile, in the case of PVP and chitosan, the produced gold nanoparticles experience great diversity of morphologies. Regarding chitosan, the rod-like shape of gold nanoparticles appeared which may be explained by the assumption that the primary amino group in chitosan made a hydrogen bond with a hydroxyl group in the same moiety or in another moiety of chitosan. This behavior enhances the crystal growth of gold nanoparticles in an elongated structure. It is clear that with manipulation of the kind and concentration of the stabilizer used in gold nanoparticle, preparation could control the morphology and aspect ratio of the produced nanoparticles.

Acknowledgements

Authors would like to acknowledge with thanks the City of Scientific Research and Technological Applications (SRTA-City) for technical support.

\section{Funding \\ No specific fund was supplied for this work.}

Availability of data and materials

All data generated or analyzed during this study are included in this published article [and its supplementary information files].

Authors' contributions

All authors contributed in the work and in writing the manuscript. All authors read and approved the final manuscript.

Ethics approval and consent to participate

The manuscript does not contain studies involving human participants, human data or human tissue.

Consent for publication

Not applicable.

Competing interests

The authors declare that they have no competing interests.

\section{Publisher's Note}

Springer Nature remains neutral with regard to jurisdictional claims in published maps and institutional affiliations.

\section{Author details}

${ }^{1}$ Chemistry Department, Faculty of Science, University of Jeddah, Jeddah, Saudi Arabia. ${ }^{2}$ Laboratory of Surface Chemistry and Catalysis, Department of Physical Chemistry, National Research Center, Al Buhouth St., Cairo, Egypt.

${ }^{3}$ Biology Department, Faculty of Science, University of Jeddah, Jeddah, Saudi 
Arabia. ${ }^{4}$ Department of Fabrication Technology, Advanced Technology and New Materials Research Institute (ATNMRI), City of Scientific Research and Technological Applications (SRTA-City), Alexandria, Egypt.

Received: 21 November 2018 Accepted: 11 February 2019

Published online: 20 February 2019

\section{References}

Abdel-Raouf N, Al-Enazi NM, Ibraheem IB (2017) Green biosynthesis of gold nanoparticles using Galaxaura elongata and characterization of their antibacterial activity. Arab J Chem 10:\$3029-\$339

Alabbad S, Adil S, Assal M, Khan M, Alwarthan A, Siddiqui MRH (2014) Gold \& silver nanoparticles supported on manganese oxide: synthesis, characterization and catalytic studies for selective oxidation of benzy alcohol. Arab J Chem 7(6):1192-1198

Allen JM, Xu J, Blahove M, Canonico-May SA, Santaloci TJ, Braselton ME et al (2017) Synthesis of less toxic gold nanorods by using

dodecylethyldimethylammonium bromide as an alternative growth-directing surfactant. J Colloid Interface Sci 505:1172-1176

Arachchige MC, Reshetnyak YK, Andreev OA (2015) Advanced targeted nanomedicine. J Biotechnol 202:88-97

Brown KR, Natan MJ (1998) Hydroxylamine seeding of colloidal Au nanoparticles in solution and on surfaces. Langmuir 14(4):726-728

Carotenuto G, Nicolais L (2004) Synthesis and characterization of gold-based nanoscopic additives for polymers. Compos Part B 35(5):385-391

Chen W, Cai W, Liang C, Zhang L (2001) Synthesis of gold nanoparticles dispersed within pores of mesoporous silica induced by ultrasonic irradiation and its characterization. Mater Res Bull 36(1-2):335-342

Corbierre MK, Cameron NS, Sutton M, Mochrie SG, Lurio LB, Rühm A et al (2001) Polymer-stabilized gold nanoparticles and their incorporation into polymer matrices. J Am Chem Soc 123(42):10411-10412

Esumi K, Hosoya T, Suzuki A, Torigoe K (2000) Preparation of hydrophobically modified poly (amidoamine) dendrimer-encapsulated gold nanoparticles in organic solvents. J Colloid Interface Sci 229(1):303-306

Esumi K, Kameo A, Suzuki A, Torigoe K (2001a) Preparation of gold nanoparticles in formamide and N, N-dimethylformamide in the presence of poly (amidoamine) dendrimers with surface methyl ester groups. Colloids Surf A Physicochem Eng Asp 189(1-3):155-161

Esumi K, Kameo A, Suzuki A, Torigoe K, Yoshimura T, Koide Y et al (2001b) Preparation of gold nanoparticles using 2-vinylpyridine telomers possessing multi-hydrocarbon chains as stabilizer. Colloids Surf A Physicochem Eng Asp 176(2-3):233-237

Huang X, El-Sayed IH, Qian W, El-Sayed MA (2006) Cancer cell imaging and photothermal therapy in the near-infrared region by using gold nanorods. J Am Chem Soc 128(6):2115-2120

Huang Z, Liu Y, Xie F, Fu Y, He Y, Ma M et al (2012) Au-supported Pt-Au mixed atomic monolayer electrocatalyst with ultrahigh specific activity for oxidation of formic acid in acidic solution. Chem Commun 48(99):12106-12108

Ibrahim AM, El-Latif MMA, Selim MM (2016) Effect of polyethyleneimine stabilizer on size and morphology of gold nanoparticles. Asian J Appl Sci 9(4):178-184

Jana NR, Gearheart L, Murphy CJ (2001) Evidence for seed-mediated nucleation in the chemical reduction of gold salts to gold nanoparticles. Chem Mater 13(7):2313-2322

Mallat T, Baiker A (2004) Oxidation of alcohols with molecular oxygen on solid catalysts. Chem Rev 104(6):3037-3058

Mena M, Yanez-Sedeno P, Pingarron J (2005) A comparison of different strategies for the construction of amperometric enzyme biosensors using gold nanoparticle-modified electrodes. Anal Biochem 336(1):20-27

Nikoobakht B, El-Sayed MA (2003) Preparation and growth mechanism of gold nanorods (NRs) using seed-mediated growth method. Chem Mater 15(10): 1957-1962

Norman RS, Stone JW, Gole A, Murphy CJ, Sabo-Attwood TL (2008) Targeted photothermal lysis of the pathogenic bacteria, Pseudomonas aeruginosa with gold nanorods. Nano Lett 8(1):302-306

Obradović MD, Gojković SL (2013) HCOOH oxidation on thin Pd layers on Au: self-poisoning by the subsequent reaction of the reaction product. Electrochim Acta 88:384-389

Panjan W, Sirijaraensre J, Warakulwit C, Pantu P, Limtrakul J (2012) The conversion of $\mathrm{CO}_{2}$ and $\mathrm{CH}_{4}$ to acetic acid over the Au-exchanged ZSM-5 catalyst: density functional theory study. Phys Chem Chem Phys 14(48):16588-16594
Pérez WI, Soto Y, Ramirez-Vick JE, Meléndez E (2015) Nanostructured gold dsDNA sensor for early detection of breast cancer by beta protein 1 (BP1). J Electroanal Chem 751:49-56

Philip D (2008) Synthesis and spectroscopic characterization of gold nanoparticles. Spectrochim Acta A Mol Biomol Spectrosc 71(1):80-85

Pol V, Gedanken A, Calderon-Moreno J (2003) Deposition of gold nanoparticles on silica spheres: a sonochemical approach. Chem Mater 15(5):1111-1118

Reed JA, Cook A, Halaas DJ, Parazzoli P, Robinson A, Matula TJ et al (2003) The effects of microgravity on nanoparticle size distributions generated by the ultrasonic reduction of an aqueous gold-chloride solution. Ultrason Sonochem 10(4-5):285-289

Sau TK, Pal A, Jana N, Wang Z, Pal T (2001) Size controlled synthesis of gold nanoparticles using photochemically prepared seed particles. J Nanopart Res 3(4):257-261

Shimmin RG, Schoch AB, Braun PV (2004) Polymer size and concentration effects on the size of gold nanoparticles capped by polymeric thiols. Langmuir. 20(13):5613-5620

Stone J, Jackson S, Wright D (2011) Biological applications of gold nanorods. Wiley Interdiscip Rev Nanomed Nanobiotechnol 3(1):100-109

Suneetha SCA, Raghupathy BPC, Suresh P (2014) Physicochemical characterization and cytotoxicity screening of a novel colloidal nanogoldbased phenytoin conjugate. Sci Pharm 82(4):857-872

Teranishi T, Kiyokawa I, Miyake M (1998) Synthesis of monodisperse gold nanoparticles using linear polymers as protective agents. Adv Mater 10(8): 596-599

Teranishi T, Kurita R, Miyake M (2000) Shape control of Pt nanoparticles. J Inorg Organomet Polym 10(3):145-156

Wu Z-H, Tseng W-L (2011) Combined cloud point extraction and Tween 20stabilized gold nanoparticles for colorimetric assay of silver nanoparticles in environmental water. Anal Methods 3(12):2915-2920

Zeng S, Yong K-T, Roy I, Dinh X-Q, Yu X, Luan F (2011) A review on functionalized gold nanoparticles for biosensing applications. Plasmonics 6(3):491

Zheng N, Fan J, Stucky GD (2006) One-step one-phase synthesis of monodisperse noble-metallic nanoparticles and their colloidal crystals. J Am Chem Soc 128(20):6550-6551

Zhu H, Tao C, Zheng S, Li J (2005) One step synthesis and phase transition of phospholipid-modified Au particles into toluene. Colloids Surf A Physicochem Eng Asp 257:411-414

\section{Submit your manuscript to a SpringerOpen ${ }^{\circ}$ journal and benefit from:}

- Convenient online submission

- Rigorous peer review

- Open access: articles freely available online

High visibility within the field

- Retaining the copyright to your article

Submit your next manuscript at $\boldsymbol{\nabla}$ springeropen.com 